\title{
Research on Comprehensive Evaluation Methods of Existing Public Buildings Based on Diamond Evaluation Method
}

\author{
Gao Yubo ${ }^{1, *}$, Mao Mingwei ${ }^{1, a}$ \\ ${ }^{1}$ Department of Architecture, Taiyuan University of Technology, Wan Berlin, Taiyuan, Shanxi, China
}

\begin{abstract}
Based on the analysis of characteristics of existing public buildings, a comprehensive method based on the diamond evaluation is established, which is integrated by the physical performance and the user's physical experiences. The method combines objective and subjective evaluations. It can divide the comprehensive value of existing public buildings in four aspects: function, economy, satisfaction, and value. Then, it explores the process and technical route of the existing public buildings using the analytic hierarchy of comprehensive evaluation. The article intends to use this method to conduct an comprehensive evaluation of Taiyuan Workers' Cultural Palace.
\end{abstract}

\section{Introduction}

There is a huge stock of existing public buildings in our country. Many existing public buildings cannot fully meet the needs of production and life at this stage, due to the constraints of their construction years and conditions. To transform and reuse the existing public buildings, scientific comprehensive value evaluation is an important link. Although a large number of evaluation studies are used in existing public buildings, none of methods gains a universal recognition. In the process of practical operation, the evaluation of existing public buildings often apply some evaluation standards of historical preservation buildings. Facing the existing public buildings with abundant types, large numbers, and different preservation states, how to construct a scientific comprehensive evaluation method for comprehensive evaluation of existing public buildings is a problem. There is a great significance to establish an index system and evaluation model for existing public buildings. Using a method to provide some basis, it can help the evaluation and reconstruction of existing public buildings.

\section{Connotation of comprehensive evaluation of existing public buildings}

Existing public buildings refer to public buildings that have been completed for a certain period of time. Compared to the concept of new buildings, it may exist generally 20 years or more. The forms of reuse the existing public buildings are mainly divided into three types: restoration, protection and renew. Restoration is to restore the inherent appearance with a specific historical period. Protection is mainly to protect the material foundation of the existing public building body while continuing its original basic style. Renew refers to the reinforcement and transformation of the buildings. The basis of building reuse is to evaluate existing public buildings and obtain their comprehensive status information. This research is based on our country's actual national conditions and practical requirements, which cannot be divorced from actual empty talk theory. We strive to achieve scientific and reasonable evaluation conclusions by objective and subjective evaluation perspectives. The index system should be comprehensive and well-defined to ensure the applicability of the evaluation system.

\section{Construction of a comprehensive evaluation system for existing public buildings}

\subsection{Evaluation mechanism of the diamond law}

The diamond method ${ }^{1}$ was proposed by William Pena ${ }^{2}$, who created a practical and feasible self-evaluation method in the planning stage and applied it to practice. Pena believed that evaluation should be measured from four aspects: function, form, economy and time. In these four aspects, score the quality of each aspect and set it from 1 point of "complete failure" to 10 points of "perfect". As shown in Figure 1, the quadrilateral is composed of function, form, economy, and time. The area of the quadrilateral is determined by the following formula: area $=0.5$ (function + time) (form + economy). The area of the quadrilateral represents the evaluation result (Fig.1). In this way, the indicators were quantified and the evaluation results were obtained ${ }^{3}$. The diamond evaluation method is simple and clear, easy to operate, and avoids the overall problem of being too trivial and paying attention to details. On the other hand, the person who conducts building evaluation is often an architect. Too much complexity may cause the architect to be out of control.There is no

\footnotetext{
* Corresponding author: 491372453@qq.com

a maomingwei@126.com
} 
feasibility in actual project practice.

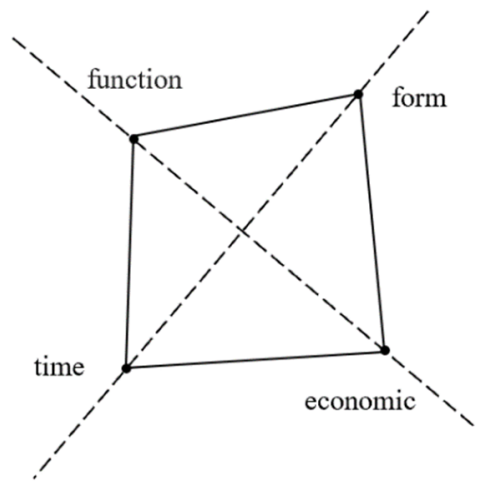

Fig. 1. Diamond Evaluation Method

\subsection{Evaluation index system for existing public buildings}

The four aspects(form, function, time, and economy) are included in the diamond evaluation method, which cannot cover the characteristics of existing public buildings. The diamond evaluation method is an evaluation method used in the construction planning stage. Based on the content of the Diamond Evaluation Method, and combined with the characteristics of existing public buildings, the author has constructed a comprehensive evaluation index system for existing public buildings. The index system is divided into three levels of indicators. The overall target level is the evaluation target "the comprehensive evaluation index system for existing public buildings. The first level indicators include 4 items, namely function, economy, satisfaction, and value, among them, function and economy are more important. The objective evaluation of building physical performance category, value and satisfaction are mainly the subjective evaluation of the user's physical experience, there are 12 secondary indicators. The specific indicator system is shown in Figure 2.

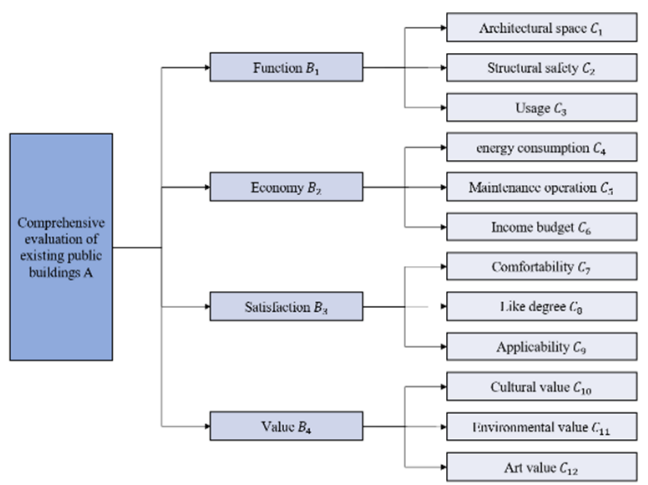

Fig. 2. Index system for comprehensive evaluation of existing public buildings

After multiplying the score of the second-level index multiply its corresponding weight, the score of the four first-level indexes can be obtained respectively. According to the calculation method of the diamond evaluation method, the quadrilateral area are enclosed by the corresponding score values of the 4 first-level indicators.
Because the four first-level indicators take the full score of 10 , the highest value of the quadrilateral area is 200 , and converting it to a percentage system can make the result more intuitive and easier to understand. It can be obtained that the final score of comprehensive evaluation of existing public buildings is:

$$
\mathrm{A}=\frac{1}{4}\left(B_{1}+B_{2}\right)\left(B_{3}+B_{4}\right)
$$

\section{Validated research on comprehensive evaluation of existing public buildings}

\subsection{Overview of evaluation objects}

Taiyuan Workers' Cultural Palace (Figure 3), which is also called Nangong, covers an area of 60,000 square meters, and with a building area of 30,000 square meters. It is the largest cultural activity center for employees in Shanxi Province. The Nangong was completed on February 15, 1958. It was designed by the Shanxi Provincial Architectural Engineering Design Institute. It is a cultural and leisure place for the city's employees. It was also a larger public civil building in Taiyuan at that time. The whole building has one auditorium (theater), two lecture halls, two production technology research rooms, two east and west exhibition halls, and two east and west corridors, which can accommodate more than 6000 employees for cultural and entertainment activities at the same time. The building is a Soviet-like building with three stories high in the middle. The corridors on both sides are connected to two-story small buildings. The whole building is like an airplane, which is eagered to fly. Nangong is the center of Taiyuan's cultural, sports, and entertainment activities. The colorful square cultural activities and large-scale theatrical performances has greatly activated the leisure life of the majority of employees and citizens.
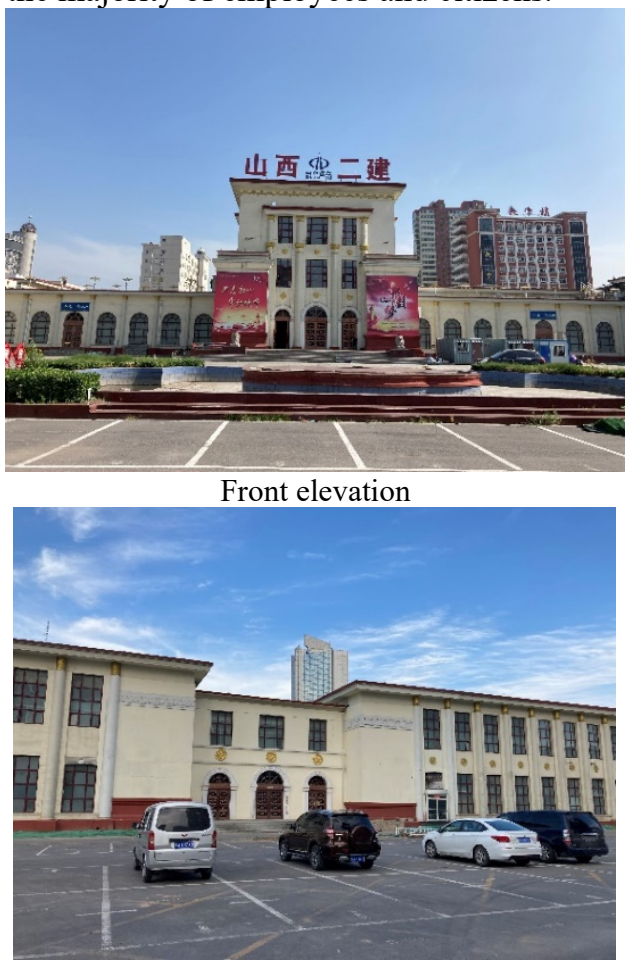

Side elevation 


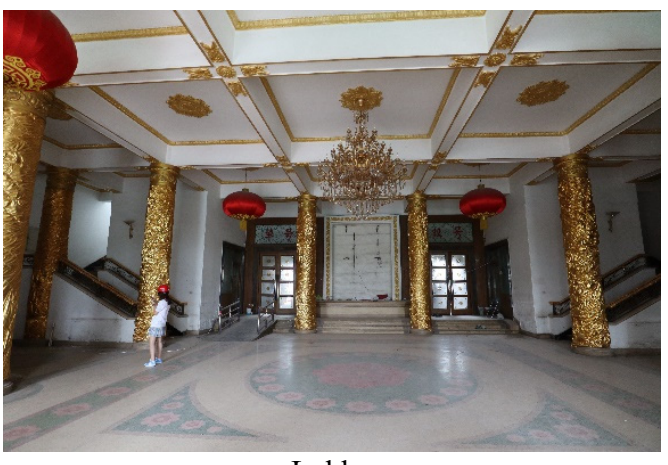

Lobby

Fig. 3 Taiyuan Workers' Cultural Palace

\subsection{Index score}

According to the characteristics and circumstances of the case, the Delphi method ${ }^{4}$ was used to organize experts to score each building index, and the quantitative assignment of each index was between 0 and 10 (Table 1).

Table 1. Setting Word's margins.

\begin{tabular}{|c|c|c|c|c|}
\hline $\begin{array}{c}\text { Overall } \\
\text { target }\end{array}$ & First-level index & Second-level index & $\begin{array}{c}\text { Sco } \\
\text { re }\end{array}$ & Weight \\
\hline \multirow{12}{*}{$\begin{array}{l}\text { Comprehen } \\
\text { sive } \\
\text { evaluation } \\
\text { of existing } \\
\text { public } \\
\text { buildings A }\end{array}$} & \multirow{3}{*}{ Function $B_{1}$} & Architectural space $C_{1}$ & 6 & 0.2500 \\
\hline & & Structural safety $C_{2}$ & 5 & 0.5000 \\
\hline & & Usage $C_{3}$ & 5 & 0.2500 \\
\hline & \multirow{3}{*}{ Economy $B_{2}$} & energy consumption $C_{4}$ & 6 & 0.4000 \\
\hline & & Maintenance operation $C_{5}$ & 7 & 0.2000 \\
\hline & & Income budget $C_{6}$ & 8 & 0.4000 \\
\hline & \multirow{3}{*}{ Satisfaction $B_{3}$} & Comfortability $C_{7}$ & 7 & 0.3333 \\
\hline & & Like degree $C_{8}$ & 7 & 0.3333 \\
\hline & & Applicability $C_{9}$ & 8 & 0.3333 \\
\hline & \multirow{3}{*}{ Value $B_{4}$} & Cultural value $C_{10}$ & 9 & 0.3333 \\
\hline & & Environmental value $C_{11}$ & 8 & 0.3333 \\
\hline & & Art value $C_{12}$ & 10 & 0.3333 \\
\hline
\end{tabular}

It can be seen from Table 1 that the index score vectors $\mathrm{R}$ corresponding to the first-level indexes are:

Function index score vector: $R_{1}=\left[\begin{array}{l}6 \\ 5 \\ 5\end{array}\right]$

Economic indicator scoring vector: $R_{2}=\left[\begin{array}{l}6 \\ 5 \\ 5\end{array}\right]$

Satisfaction index score vector: $R_{3}=\left[\begin{array}{l}6 \\ 5 \\ 5\end{array}\right]$

Value index score vector: $\mathrm{R}_{4}=\left[\begin{array}{l}6 \\ 5 \\ 5\end{array}\right]$

\subsection{Weight setting}

According to the Delphi method and analytic hierarchy process, experts are organized to judge the importance of each building index. The corresponding weights of the secondary indexes are shown in Table 1 . The weight vector $\mathrm{W}$ corresponding to the first-level index is:

Function index weight vector:

$W_{1}=\left[\begin{array}{lll}0.4000 & 0.2000 & 0.4000\end{array}\right]$

Economic indicator weight vector:

$W_{2}=\left[\begin{array}{lll}0.4000 & 0.2000 & 0.4000\end{array}\right]$

Satisfaction index weight vector:

$W_{3}=\left[\begin{array}{lll}0.3333 & 0.3333 & 0.3333\end{array}\right]$

Value index weight vector:

$W_{4}=\left[\begin{array}{lll}0.3333 & 0.3333 & 0.3333\end{array}\right]$

\subsection{Weight setting}

Multiply the weight vector $\mathrm{W}$ correspond to the first-level index by the score vector $\mathrm{R}$ to obtain the evaluation result of the first-level index, as follows:

Function index score:

$B_{1}=W_{1} \times R_{1}=5.25$

Economic indicator score:

$B_{2}=W_{2} \times R_{2}=7$

Satisfaction index score:

$B_{3}=W_{3} \times R_{3}=7.3$

Value index weight vector:

$B_{4}=W_{4} \times R_{4}=9$

According to the rules of the index system constructed above, the comprehensive evaluation score of Taiyuan Workers' Cultural Palace is equal to the quadrilateral area enclosed by the four values of function $\mathrm{B}_{1}$, economy $\mathrm{B}_{2}$, satisfaction $B_{3}$, and value $B_{4}$ :

$$
\mathrm{A}=\frac{1}{4}\left(B_{1}+B_{2}\right)\left(B_{3}+B_{4}\right)=50
$$

According to the full score of 100, the comprehensive evaluation of Taiyuan Workers' Cultural Palace is good. Specifically, the function of the building is general, because the original space inside the house is seriously damaged.There are major safety hazards due to leaks in multiple roofs. The economy of the building is good, and its scale is large, and the storey height is high. The space is flexibly arranged, and its reconstruction and utilization have considerable economic benefits. The satisfaction of the building is good, and its social identity in the hearts of the city residents is high. It is a typical cultural landmark building. The value of the building is also excellent.It not only has distinctive features in appearance and style, but also contributes a lot to its rich historical background information and cultural symbolic alignment.

\section{Summary}

The comprehensive evaluation index of existing public buildings is based on the summary of domestic and foreign related evaluation systems. The diamond evaluation method is the core concept, which combined the actual characteristics of existing public buildings in my country. The evaluation indexes are divided into four aspects : function, economy, satisfaction, and value. This division can take into account the basic logic and content of the diamond evaluation method, and it also integrate the objective evaluation of the physical properties of the building and the subjective evaluation of the user's experience.The existing comprehensive evaluation index system for public buildings has a comprehensive 
characteristics.

In terms of research methods, the Delphi method and analytic hierarchy process, which is widely used in the industry,established a quantitative mechanism for evaluation indicators ${ }^{5}$.A judgment matrix is constructed to determine the corresponding weights of the indicators , and to increase the credibility and scientific of the evaluation. Through the evaluation of existing public buildings, we can have a more comprehensive grasp of the current advantages and disadvantages of the buildings, so as to assist in determining the strategy and focus of the protection and reuse of the building.

\section{Acknowledgment}

This article is one of the phased achievements of the key research and development project in Shanxi Province, China, "Shanxi Province Existing Building Performance Evaluation and Renovation Technology Research" (201903D32035).

\section{References}

1. William Pena, Steven Parshall. Problem Seeking: An Architectural Programming Primer[M]. John Wiley \& Sons Inc. 2001:209

2. Mallows Edward teaching a technology[M]. Johannesburg: Witwatersrand University press, 1965

3. Zhuang Weimin, Zhang Wei, Liang Sisi. Architectural planning and post-evaluation[M]. China Construction Industry Press. 2018

4. Jiang Nan. Technology and method of industrial heritage value evaluation based on adaptive reuse[J]. New Building.2016(3):4-9

5. Zhang Chengxing, Wang Xiaofeng, Li Yitong. Research on the comprehensive performance evaluation index system of existing public building renovation[J]. Building Energy Conservation. 2019 (10): 138-141 